\title{
IUFOST2006/1182 \\ EUROAGRI+ to strengthen the competitiveness of food companies trough innovation and crossborder collaboration
}

\author{
J.-C. Villettaz \\ EUROAGRI+, haute école valaisanne, Rawyl 47, 1950 Sion, Switzerland \\ jclaude.villettaz@hevs.ch
}

\begin{abstract}
EUROAGRI+ is the EUREKA Umbrella specifically dedicated to European Agriculture, Food and Feed industry. It covers the entire food chain often referred to as 'field to table'. The main goal of EUROAGRI+ is to strengthen the whole agri-food chain, helping agriculture, food and feed companies to develop new products, technologies and services with the highest value in terms of quality and safety. EUROAGRI+ main caracteristics are the following: SME friendly, non bureaucratic, bottom-up approach, market driven, quick decision procedures. The project leadership remains in the hands of the participating companies as well as the intellectual properties rights. The project size is also defined by the participating enterprises according to the work to be done and the amount of money they want to spend on the project. Regarding the main advantages as perceived by the managers of the participating companies, one can point out the following: light and quick procedures, project management in the hands of the participating companies, acquisition of know how, development of innovative products and services, extention of the existing business network, easier access to other European markets, risk and cost sharing with the best partners. Following the advice 'If you can not beat them, join them', EUROAGRI+ is a powerful platform to help SME's to develop ME-FIRST products, technologies, or services through crossborder collaboration with the best possible European companies. For more informations visit www.euroagri.org
\end{abstract}

